Cinémas

Revue d'études cinématographiques

Journal of Film Studies

\title{
Notes sur les collaborateurs
}

Volume 9, numéro 1, automne 1998

Les Dispositifs de médiation au cinéma

URI : https://id.erudit.org/iderudit/024781ar

DOI : https://doi.org/10.7202/024781ar

Aller au sommaire du numéro

Éditeur(s)

Cinémas

ISSN

1181-6945 (imprimé)

1705-6500 (numérique)

Découvrir la revue

Citer ce document

(1998). Notes sur les collaborateurs. Cinémas, 9(1), 167-168.

https://doi.org/10.7202/024781ar d'utilisation que vous pouvez consulter en ligne.

https://apropos.erudit.org/fr/usagers/politique-dutilisation/ 


\section{Notes sur les collaborateurs}

Serge Cardinal est étudiant au doctorat en sémiologie à l'Université du Québec à Montréal. Ses recherches portent sur le son et l'espace au cinéma. Il a réalisé deux moyens métrages: Brèves rencontres et légers penchants, L'Invention d'un paysage.

PaOlo CherChI USAI est conservateur au Film Department de la George Eastman House/International Museum of Photography and Film, Rochester, New York. Il est cofondateur du Pordenone Silent Film festival et de Domitor. Ses travaux de recherche portent sur l'histoire et l'esthétique des films; il se consacre notamment à l'examen des périodes, des personnalités et des œuvres négligées, dès le début du cinéma jusqu'à l'avènement du parlant. Il a publié plusieurs ouvrages, dont Burning Passions: An Introduction to the Study of Silent Cinema et The Vitagraph Company of America (1897-1916).

KATHRYN FRASER est étudiante au doctorat en communications à l'Université McGill. Son domaine de recherche est orienté vers la culture du consommateur, la psychoanalyse, le cinéma et le spectateur.

GERMAIN LACASSE est historien et chargé de cours à l'Université du Québec à Montréal. Il a publié quelques livres sur les premiers temps du cinéma au Québec, notamment Histoires de scopes. Le cinéma muet au Québec (1988) et Au pays des ennemis du cinéma (avec A. Gaudreault et J. P. Sirois-Trahan, 1996). Son prochain livre paraîtra en 1999: Le Bonimenteur et le cinéma oral. Les «vues animées» entre tradition et modernité.

GÉRARd Leblarnc est maître de conférence à l'université de Paris III (UFR Cinérna et audiovisuel). Ses recherches portent autant sur le cinéma que sur la télévision. Il a publié de nombreux ouvrages sur le cinéma et sur la télévision, notamment Le Double Scénario chez Fritz Lang (en coll. avec Brigitte Devismes), Armand Colin, 1991, Georges Franju, une esthétique de la déstabilisation, La Maison de la Villette, 1992, Les Télévisions dans le monde (en coll. avec François Jost), Anthropos, 1994, et Scénarios du réel, l'Harmattan, 1997. 
DOMinique MALENFANT-GamaCHE est étudiante à la maîtrise en études cinématographiques au Département d'histoire de l'art de l'Université de Montréal. Son domaine de recherche est le collage électronique dans l'art vidéo.

Charles Perraton est professeur au département des communications de l'Université du Québec à Montréal. Il est professeur invité au Département des sciences et techniques de la communication (DESTEC) de l'Université de la Sorbonne NouvelleParis III au printemps 1996. D'une recherche centrée sur la saisie du sens des espaces publics et des pratiques qui y sont rattachées, il est passé à l'analyse des rapports qu'entretiennent l'architecture et le cinéma dans la structuration des individus et dans la (re)configuration générale de leurs espaces d'action. Il en a publié les résultats dans différents ouvrages en collaboration [avec notamment Du simple au double (1995), Un siècle en courts (1996), Le corps différé (1998)] et articles de revues [dont Protée (1984, 1990 et 1991), Revue d'Esthétique (1986), Cinémas (1995), RS/SI (1995), Géographie et société (1998)]. Il est responsable du Groupe d'études et de recherches en sémiotique des espaces (Gerse) à l'Université du Québec à Montréal.

Jun SATO est réalisateur de films documentaires et chercheur à la Formation de Recherches Cinématographiques de l'université de Paris X-Nanterre. Il a notamment publié De l'espace à l'écran (1991), et réalisé Forum des Halles I, II, III (1980 et 1982) ainsi que Promenade aux Halles (1985).

JEAN-PhILIPPE UZEL est professeur au Département d'histoire de l'art de l'Université du Québec à Montréal. Il est détenteur d'un doctorat en science politique (Université Pierre Mendès France Grenoble), d'une maîtrise en sciences de l'information et de la communication (Université Stendhal - Grenoble) et d'une maîtrise en études des arts (Université du Québec à Montréal). Ses recherches portent, d'une façon générale, sur les relations entre l'art et la politique.

Mike Vienneau est étudiant au doctorat au Département de littérature comparée de l'Université de Montréal. Son mémoire de maîtrise en études cinématographiques portait sur le cinéaste Alain Resnais. 